\title{
Time for anisotropy: The significance of mechanical anisotropy for the development of deformation structures
}

Hao Ran ${ }^{1,2}$, Tamara de Riese ${ }^{1}$, Maria-Gema Llorens ${ }^{1,3}$, Melanie A. Finch ${ }^{1}$, Lynn A. Evans ${ }^{4}$, Enrique Gomez-Rivas $^{5,6}$, Albert Griera ${ }^{3}$, Mark W. Jessell ${ }^{7}$, Ricardo A. Lebensohn ${ }^{8}$, Sandra Piazolo ${ }^{9}$ and Paul D. Bons ${ }^{1, *}$

1 Department of Geosciences, Eberhard Karls University Tübingen, Germany

2 School of Earth Sciences and Resources, China University of Geosciences, Beijing,

China

3 Departament de Geologia, Universitat Autònoma de Barcelona, Spain

4 School of Earth, Atmosphere and Environmental Sciences, Monash University,

Clayton, Victoria, Australia

5 Department of Mineralogy, Petrology and Applied Geology, University of

Barcelona, Barcelona, Spain

6 School of Geosciences, King's College, University of Aberdeen, Aberdeen, UK

7 Centre for Exploration Targeting, School of Earth Sciences, The University of

Western Australia, Crawley, Western Australia, Australia

8 Material Science and Technology Division, Los Alamos National Laboratory, USA

9 School of Earth and Environment, University of Leeds, Leeds, UK

*Corresponding author: Department of Geosciences, Eberhard Karls University,

Wilhelmstr. 56, 72074 Tübingen, Germany. Tel.: +49-7071-2976469.

paul.bons@uni-tuebingen.de

This article is published in the Journal of Structural Geology (2019), 125, 41-47. DOI:

doi.org/10.1016/j.jsg.2018.04.019. This is an author's version of the manuscript. To

download the final copy-edited version please visit:

https://www.sciencedirect.com/science/article/pii/S0191814118300087 


\section{Time for anisotropy: The significance of mechanical anisotropy for the development of deformation structures}

Hao Ran ${ }^{1,2}$, Tamara de Riese ${ }^{1}$, Maria-Gema Llorens ${ }^{1,3}$, Melanie A. Finch ${ }^{1}$, Lynn A. Evans $^{4}$, Enrique Gomez-Rivas ${ }^{5,6}$, Albert Griera ${ }^{3}$, Mark W. Jessell7 , Ricardo A. Lebensohn ${ }^{8}$, Sandra Piazolo ${ }^{9}$, Paul D. Bons ${ }^{1, *}$

${ }^{1}$ Department of Geosciences, Eberhard Karls University Tübingen, Germany ${ }^{2}$ School of Earth Sciences and Resources, China University of Geosciences, Beijing, China

${ }^{3}$ Departament de Geologia, Universitat Autònoma de Barcelona, Spain ${ }^{4}$ School of Earth, Atmosphere and Environmental Sciences, Monash University, Clayton, Victoria, Australia

${ }^{5}$ Department of Mineralogy, Petrology and Applied Geology, University of Barcelona, Barcelona, Spain ${ }^{6}$ School of Geosciences, King's College, University of Aberdeen, Aberdeen, UK ${ }^{7}$ Centre for Exploration Targeting, School of Earth Sciences, The University of Western Australia, Crawley, Western Australia, Australia ${ }^{8}$ Material Science and Technology Division, Los Alamos National Laboratory, USA ${ }^{9}$ School of Earth and Environment, University of Leeds, Leeds, UK

*Corresponding author: Department of Geosciences, Eberhard Karls University, Wilhelmstr. 56, 72074 Tübingen, Germany. Tel.: +49-7071-2976469. paul.bons@uni-tuebingen.de

\section{Keywords}

Mechanical anisotropy; porphyroclasts; strain localisation; folds; shear zones

\section{Abstract}

The forty-year history of the Journal of Structural Geology has recorded an enormous increase in the description, interpretation and modelling of 
deformation structures. Amongst factors that control deformation and the resulting structures, mechanical anisotropy has proven difficult to tackle. Using a Fast Fourier Transform-based numerical solver for viscoplastic deformation of crystalline materials, we illustrate how mechanical anisotropy has a profound effect on developing structures, such as crenulation cleavages, porphyroclast geometry and the initiation of shear bands and shear zones.

\section{Introduction}

Structural geologists have used a range of structures to determine deformation histories of rocks (e.g. Treagus, 1982; Ramsay and Huber, 1987; Hudleston and Lan, 1993; Passchier and Trouw, 2005). Many of these structures, such as folds and structures around rigid objects (i.e. porphyroclasts and porphyroblasts) are controlled by contrasts in the mechanical properties of the different minerals involved. These structures are therefore typically treated as inclusion-matrix (IM) systems, with typically a stronger inclusion phase (porphyroclasts, boudins, folding layers) embedded in a softer matrix.

To improve and quantify the interpretation of structures observed in the field, geologists have developed increasingly complex models for IM systems. Initially these were based on pioneering analytical models, such as those by Jeffery (1922), Eshelby (1957) and Ramberg (1962) for rotation of elliptical inclusions and Biot (1961) for folding of a single layer in a softer matrix. Taylor (1938) recognised the importance of the anisotropy of crystal plasticity to the development of crystallographic preferred orientations, and Kamb (1972) first explained how this could modify dynamic recrystallization in ice. The 40-year history of the Journal of Structural Geology has seen the advent and blossoming of numerical modelling to simulate a range of IM structures, thus helping geologists to understand how they form. Since the earliest computer simulations, models have steadily increased in sophistication and resolution. Early computers were usually restricted to linear, Newtonian rheology (e.g. Dieterich, 1970). Nonlinear rheology, assumed common in rocks (Kirby, 1983; Carter and Tsenn, 1987), has now become a standard ingredient in models (Huddleston and Lan, 1994; Bons et al., 1997; Jessell et al., 2009; Mancktelow, 1999; 2011; Schmalholz 
and Maeder, 2012; Llorens et al., 2013a; Gardner et al. 2017). Boundary conditions in early models were usually restricted to pure shear conditions. However, many natural high-strain structures of interest typically develop in mylonites that deform close to simple shear (e.g. Passchier and Trouw, 2005; Gomez-Rivas et al., 2007). Simple shear deformation was therefore already applied to these IM systems early on (Jezek, 1994; Bons et al. 1997), but, for example, systematic modelling of folding in simple shear started much later (Viola and Mancktelow, 2005; Llorens et al., 2013a,b). The steadily increasing calculation speed of computers has allowed modellers to reach ever-higher finite strains (e.g. Schmalholz et al., 2001; Jessell et al., 2009; Dabrowski and Schmid, 2011; Dabrowski et al., 2012; Grasemann and Dabrowski, 2015). Additional factors and processes, such as shear heating, strain softening, slipping phase boundaries, grain-size effects, etc. have also been incorporated in models (Schmalholz and Podladchikov, 1999; Marques et al., 2005a,b, 2014; Schmalholz, 2006; Hobbs et al., 2008; Mancktelow, 2013; Montagnat et al., 2014; Gardner et al., 2017, among others).

Despite the enormous progress in IM-system modelling, there seems to be one elephant left in the room that is still commonly overlooked or ignored in these numerical models: anisotropy. Many material properties are known to be highly anisotropic in rocks and minerals, including magnetism, thermal expansion, elasticity, surface energy and mineral slip system activity. Early numerical simulations studies recognised the importance of mechanical anisotropy to the production of crystallographic preferred orientations in rocks (Taylor, 1938; Kröner, 1961;Etchecopar, 1977; Lister et al., 1978), and these have also been shown to be significant in the formation of larger-scale geological structures. For example, a field geologist would probably interpret the structure in Fig. 1a as follows (Druguet et al., 1997): the rock is a foliated biotite schist with a first foliation $S_{1}$ formed by aligned biotite grains. The foliated schist and a younger quartz vein were then deformed in a second event $\left(D_{2}\right)$, which led to buckle folds in the vein and the formation of an axial-planar crenulation cleavage $\left(S_{2}\right)$ in the schist. The quartz vein folds are comparable with those in numerical simulations and these folds from Cap de Creus (Spain) have indeed been used to compare with and validate numerical models (Llorens et al., 2013a,b). However, 
folds in the matrix look completely different. Whereas the quartz vein forms approximately parallel buckle folds, the crenulations in the schist are closer to similar folds (Fig. 1a). Structural geologists are aware that this is because the schist already has a distinct $\mathrm{S}_{1}$-foliation, and is, therefore, strongly anisotropic. Although the importance of anisotropy for folding is known for decades (e.g. Baily, 1970; Cobbold et al., 1971; Fletcher, 1974; Watkinson, 1983; Weijermars, 1992; Zhang et al., 1993), most numerical simulations have been of buckle folds in isotropic matrices (see Hudleston and Treagus (2010) for a review), with relatively few exceptions, mostly dealing with chevron folds (Mühlhaus et al., 2002; Kocher et al., 2006, 2008; Jansen et al., 2016; Schmalholz and Mancktelow, 2016). This example illustrates clearly that mechanical anisotropy needs to be taken into account when realistically modelling geological structures. Below we give examples of incorporating the effect of mechanical anisotropy in simulations of folding, $\sigma-/ \delta$-clast formation and shear localisation.

In the following section, we present a numerical method that allows geologists to assess the influence of anisotropy in the development of geological structures. This is followed by a number of examples of models highlighting the fact that anisotropy of material properties may be one of the "missing" keys to understand geological structures, holding much promise for future investigations.

\section{The full-field crystal plasticity approach}

At the grain scale, the crystal structure results in anisotropic behaviour of many physical properties. This is particularly relevant for viscous deformation accommodated by dislocation glide along particular slip systems (Frost and Ashby, 1983). Montagnat et al. (2014) provide an example of the many approaches that have been applied to model single- and polycrystal deformation of the mechanically highly anisotropic mineral ice Ih. Here, our simulations of polycrystalline aggregates with intrinsic anisotropy (i.e. anisotropy well developed at all scales) are based on the full-field VPFFT crystal plasticity code (Lebensohn, 2001), which calculates the viscoplastic deformation for a polycrystalline aggregate using a Fast Fourier Transform-based numerical solver. The VPFFT code solves the micromechanical problem by finding the strain rate 
and stress fields that minimize the average local work-rate satisfying the constitutive relation at local level, under the constraints of strain compatibility and stress equilibrium (see Lebensohn (2001), Lebensohn et al. (2008; 2009) and Montagnat et al. (2014) for a more detailed description of the theoretical framework and the numerical algorithm, and Griera et al. (2013) and Llorens et al. $(2016 a, b)$ for the coupling with the ELLE microstructural simulation platform).

In geology the coupling of the full-field crystal plasticity VPFFT (Viscoplastic Full-Field Transform) method by Lebensohn (2001), Lebensohn et al. (2008) and the ELLE microstructural simulation platform (Jessell et al., 2001; Bons et al., 2008; Piazolo et al. 2010; http://www.elle.ws) has allowed the systematic simulation of deformation and recrystallization of polycrystalline rocks (such as ice and halite, e.g. Griera et al., 2011; 2013; Llorens et al., 2016a,b; 2017; Steinbach et al., 2016, 2017; Gomez-Rivas et al., 2017). In these cases, the polycrystalline aggregate is discretised into a periodic, regular mesh of nodes that store properties such as lattice orientation and dislocation density. These nodes act as Fourier Points in the VPFFT code and as unconnected nodes (unodes) in ELLE routines. Therefore, the integration between VPFFT and ELLE is based on the direct one-to-one mapping between the data structures of the two approaches. It is important to note that the VPFFT method is essentially scale independent and can therefore be used to simulate geological structures that have an inherent mechanical anisotropy ranging from small-scale (e.g. shear sense indicators, grain scale stress heterogeneities) to large-scale features (e.g. layers with contrasting rheology).

Here, we present a number of examples utilizing the VPFFT-ELLE method. In these examples the mechanical properties of the polycrystal are simulated assuming a "numerical mineral" with hexagonal symmetry, as was used by Griera et al. $(2011 ; 2013)$ to model porphyroclast/-blast systems. With this symmetry, deformation is allowed to be accommodated by glide on the basal plane (basal slip) and along non-basal planes (pyramidal and prismatic slip). In this approach the grain anisotropy parameter $(A)$ that accounts for the degree of anisotropy is defined as the ratio of the critical resolved stresses ( $\left.\tau_{\mathrm{cr}}\right)$ of the nonbasal basal and basal slip systems (e.g. Lebensohn et al., 2009). $A$ is comparable 
to the ratio between normal and shear viscosity as employed by e.g. Mühlhaus (2002) and Kocher et al. (2006, 2008). For all examples, a stress exponent of $n=3$ is assumed for all slip systems.

\section{Examples}

In the following, examples we contrast the effect of different material behaviour in terms of anisotropy on the characteristics of developing geological structures during deformation.

\subsection{Single layer folding: The effect of matrix anisotropy}

In our example, we first show deformation of a layer embedded in an isotropic matrix, using a non-linear viscous finite element method (BASIL, Houseman et al., 2008) within ELLE (Fig. 1b-c). BASIL is a finite element deformation module that simulates viscous deformation of a 2D sheet in plane-strain. BASIL can be coupled within ELLE in order to calculate the viscous strain rates and the associated stress field for different boundary conditions (i.e. from pure to simple shear). The grid of regularly spaced unconnected nodes (unodes) is used to track the deformation history and deformation field through passive lines initially parallel to the folding layer. ELLE uses both horizontally and vertically wrapping boundaries, allowing the model to be periodic in all directions. This approach reduces detrimental boundary effects and simplifies visualisation of the model at very high strains. See Jessell et al. (2005), Bons et al. (2008), and Jessell et al. (2009) for details about BASIL and ELLE.

In our simulations, we assigned homogeneous rheological properties to the polygons (Fig. 1b-c) that define the layer and matrix. With no variation in properties within the material, perturbations in the layer surface are critical for the resulting folds (Mancktelow, 1999; Zhang et al., 2000). Small variations in layer thickness were therefore introduced to initiate folding, as in Llorens et al. (2013a,b). 
Figures $1 \mathrm{~b}$ and $1 \mathrm{c}$ show the results for folding a single layer in simple and in pure shear, respectively. In BASIL, the rheology is defined by a power-law of the type:

$$
\dot{\varepsilon}=\sigma^{n} / B,
$$

with $\dot{\varepsilon}$ the strain rate and $\sigma$ the differential stress. The competence contrast between layer and matrix is defined here by the ratio of $B_{\text {layer }} / B_{\text {matrix }}$, set to 50 here (Table 1). Passive grid lines, originally parallel to the competent layer, show the deformation within the matrix. Folding decreases in intensity away from the "zone of contact strain" (Ramberg, 1962) near the layer, and strain is approximately homogeneous at the lateral edges of the model.

In Fig. 1d-e, we present two numerical simulations of single competent layer folding in an anisotropic matrix using the VPFFT-ELLE code with powerlaw rheology. Initially, the basal slip plane of grains (individual square elements in the 256x256 element model) in the matrix were aligned approximately parallel to the layer. Therefore, starting models can be regarded as representing a foliated or mica-rich rock with anisotropy. The noise to initiate folding now derives from the small random variations in lattice orientation in the layer and matrix. The competent layer was set to be isotropic, with a $\tau_{c r}$ five times higher than the non-basal slip systems of the matrix. Their $\tau_{c r}$ in turn was set at 20 times that of the basal slip system, giving an anisotropy factor $A$ of 20 (Table 1). Under pure and simple shear, the geometry of the folded single layer in the anisotropic matrix is similar to that in isotropic matrix (Fig. 1b-c). However, the geometry of microfolds represented by passive gridlines in the anisotropic matrix is very different from those in isotropic cases. The grid lines are folded in similar-type folds or crenulations that do not decay away from the competent layer (similar to results obtained by Kocher et al., 2006). Fold hinges align to form an axialplanar crenulation cleavage. The resulting geometry is similar to that of the natural example (Fig. 1a), with the passive gridlines representing $S_{1}$ and the crenulation cleavage $S_{2}$.

\subsection{Mantled porphyroclasts: $\delta$ - or $\sigma$-clasts?}


$\sigma$ - and $\delta$-clasts, or more general mantled porphyroclasts are extremely useful shear-sense indicators (Passchier and Simpson, 1986; Hanmer and Passchier, 1991; Grasemann and Dabrowski, 2015). These typically consist of a core porphyroclast with wings or tails of recrystallised material. Most studies addressed the rotation rate of isolated competent inclusions during deformation as a function of factors such as the object shape, stress exponent, and slipping object-matrix boundaries (e.g. Ghosh and Ramberg, 1976; Bons et al., 1997; Mandal et al., 2000; ten Grotenhuis et al., 2002; Schmid and Podladchikov, 2005; Fay et al., 2008; Dabrowski and Schmid, 2011; Griera et al., 2011, 2013; Mancktelow, 2011, 2013; Jiang, 2016). Although the role of anisotropy was recognised early on (e.g. Passchier et al., 1992), only Dabrowski and Schmid (2011) and Griera et al. $(2011 ; 2013)$ actually included anisotropic flow properties in their numerical models. Main outcomes of these studies are that the rotation rate and the strain field around an object are affected by anisotropy.

With a strong emphasis on the ongoing rotation versus non-rotation of porphyroblats debate (Bell et al., 1992; Passchier et al., 1992), little attention has been given to the question what causes mantles porphyroclasts to either form $\delta$ or $\sigma$ geometries. The main model is that this depends on the weakness of the mantle (or slipping interface) and its thickness relative to the size of the central object, with thick mantles forming $\sigma$-clasts and thin ones $\delta$-clasts (Passchier and Sokoutis, 1993; and review of Marques et al., 2014). Bons et al. (1997) already suggested that anisotropy of the matrix would inhibit rotation, leading to the formation of $\sigma$-clasts. Here we show an example of the effect of anisotropy on the developing shape of a mantled porphyroclast, again using the VPFFT-ELLE code.

In the isotropic case (all slip systems of one phase have the same $\tau_{c r}$; Table 1 ), the core object's $\tau_{c r}$ was set at $50 x$ that of the matrix, while that of the mantle was $0.8 \mathrm{x}$ that of the matrix. Deformation is homogeneous in case of an isotropic mantle and the central object rotates at a rate close to the analytical solution of Jeffery (1922) (Griera et al., 2011; 2013) (Fig. 2a). Wings develop by smearing out of the mantle and as the points where the wings attach to the object rotate along with the object, a $\delta$-clast develops (Fig. 2a). When the mantle is distinctly softer $\left(\tau_{c r}=4\right)$ than the object ( $\left.\tau_{c r}=50\right)$, and the matrix is anisotropic ( $A=10$, with 
$\tau_{c r}=1$ for the basal slip system and $\tau_{c r}=10$ for non-basal slip systems), deformation in the matrix is highly heterogeneous and folds and shear bands develop (Griera et al., 2011; 2013). Rotation of the object is now inhibited (contrary to the analytical model of Fletcher, 2009) and the attachment points of the wings do not rotate enough to develop the distinct embayments of $\delta$-clasts (Fig. 2b). Instead, a $\sigma$-clast forms.

These results confirm the observations of Griera et al (2013) that the incorporation of anisotropy provides an elegant way to explain controversies in structural geology regarding the duality between rotation or non-rotation of porphyroblasts (Bell et al., 1992; Passchier et al., 1992). Spiral geometries of inclusions preferentially develop in isotropic conditions, while an increase in anisotropy tends to reduce rotation of porphyroblasts of which the inclusion trails then indicate growth over a crenulated matrix.

\subsection{Shear bands in composite materials}

Structures in natural and modelled shear zones are determined in part by the strength contrast between minerals and slip systems within minerals. Weak minerals define the foliation (S-surface) at $45^{\circ}$ from the shear zone boundary, and planes progressively rotate into parallelism with the shear zone boundary and the C-surface (Fig. 3a). Less well understood is the development of $\mathrm{C}^{\prime}$ shear bands (fig. 3a), despite their ubiquity in shear zones in nature, experiments, and models (White, 1979; Platt and Vissers, 1980; Platt, 1984; Dennis and Secor, 1987). C' shear bands dip at an angle of $\sim 15-35^{\circ}$ from the shear zone boundary, in the opposite direction to the main foliation (or S plane; White, 1979; Platt and Vissers, 1980) and show synthetic, normal shear sense (Fig. 3a). They are most common in well-foliated rocks such as schists and phyllites (Passchier, 1991; Delle Piane et al., 2009) and so it has been suggested that anisotropy is required for their development (Wilson, 1984; Goodwin and Tikoff, 2002).

We used VPFFT-ELLE to model the development of $\mathrm{C}^{\prime}$ shear bands in anisotropic materials, building on the work of Jessell et al. (2009) by testing the proportion of weak phase required for the development of $\mathrm{C}^{\prime}$ shear bands in three-phase models and by introducing anisotropy to the crystallography of the 
weakest phase. The model shown (Fig. 3b) included a strong, intermediate, and a weak phase, the latter of which had a basal plane ten times weaker than prismatic and pyramidal planes (i.e. $A=10$ ). We found that $\mathrm{C}^{\prime}$ shear bands formed in all models with $>1 \%$ weak phase and were more abundant in models with a higher proportion of weak phase. In nature (Fig. 3a) and in models (Fig. 3b) C' shear bands are dominantly defined by the weakest phase.

\subsection{Shear localisation}

Shear localisation develops at almost all scales in ductile rocks. For example, the shear zones in Cap de Creus (NE Spain) are linked in an anastomosing framework with self-similar properties, where a pre-existing foliation in the metasediments have led to instabilities, forming shear zones at a wide range of scales (Druguet et al., 1997; Carreras, 2001; Fusseis et al., 2006; Schrank et al., 2008). In polar ice sheet dynamics, the behaviour of large ice masses is strongly influenced by visco-plastic anisotropy of grains and their ability to form a lattice preferred orientation (LPO) by lattice rotation (Azuma and Higashi, 1985; Alley, 1988). The flow of glaciers and polar ice sheets is controlled by the highly anisotropic rheology of Ice Ih crystals (Azuma, 1994; Bons et al., 2016; Llorens et al., 2016a,b; Llorens et al., 2017), which may lead to high strain zones in the glaciers and polar ice sheets (Marmo and Wilson, 1998) and folding (Bons et al., 2016; Jansen et al., 2016).

To show how anisotropy (defined by the parameter $A$ ) affects localisation, we simulate the deformation of a pure, single-phase polycrystal in dextral simple shear (Fig. 4) up to a shear strain of 1.5 with VPFFT-ELLE described above. Basal planes were initially randomly oriented. Strain localisation occurs only in anisotropic cases $(A>1)$, as can be seen by the passive deformation of the polygon boundaries that originally had a foam texture (Fig. 4a) and the map of the normalised Von Mises strain rate field (Fig. 4b). High strain-rate rate bands oriented at a low angle to the horizontal shear plane are clearly visible (Fig.4a and b), especially at high anisotropy values $(A>>1)$.

The frequency distribution of normalised strain rates, at a shear strain of three, in the isotropic material $(A=1)$ is approximately normal (Fig. 4c). 
Simulations with $A>1$ show frequency distribution that deviate from normal distribution (Fig. 4c) and are closer to log-normal. However, they are not exactly log-normal, as they become heavy tailed for large strain-rate values. Higher strain rate values become overrepresented with values up to 20 times the mean for $A=20$. Therefore, a material with a higher degree of anisotropy will reach significantly higher strain rate values due to strain localisation. As a result, most of the material deforms at a significantly lower rate than the mean strain rate, as can be seen by the leftward shift of the frequency peak in Fig. 4c.

\section{Discussion and conclusions}

The examples described in previous sections provide a brief glimpse into the effect of intrinsic mechanical anisotropy (Griera et al. 2013) on deformation structures in rocks. In all cases, anisotropy caused heterogeneous strain: expressed in the axial planar crenulation cleavage in Fig. 1d-e; folds and shear bands in the matrix of the $\sigma$-clast in Fig. $2 b$; and shear bands in shearing multiphase (Fig. 3) and single-phase (Fig. 4) models. The strain localisation may be the most interesting aspect here. Processes such as shear heating and grainsize reduction have been considered in detail as causes for strain localisation (Tullis and Yund, 1985; Braun et al., 1999; de Bresser et al., 2001; Bercovici, 2003; Jessell et al., 2005; Kaus and Podladchikov, 2006; Platt and Behr, 2011; Montési 2013). Mechanical anisotropy may be of equal importance, leading to shear zones from the grain scale (Fig. 3) to possibly continental sutures, similar to the damage model of Bercovice (2014).

In this paper we have used to VPFFT+ELLE numerical code to illustrate the effect of intrinsic mechanical anisotropy. We do not claim that this is the only available approach. We use this anniversary issue to encourage structural geologists to develop more analytical and numerical models to finally elucidate the role of mechanical anisotropy on all scales.

\section{Acknowledgments}


HR acknowledges financial support by the China Scholarship Council (CSC; grant nr. 201506400014). EGR acknowledges the support of the Beatriu de Pinós programme of the Government of Catalonia's Secretariat for Universities and Research of the Department of Economy and Knowledge (2016 BP 00208). We thank Bruce Hobbs and an anonymous reviewer for their suggestions to improve this article.

\section{References}

Alley, R.B., 1988. Fabrics in polar ice sheets: development and prediction. Science 240, 493-495.

Azuma, N., 1994. A flow law for anisotropic ice and its application to ice sheets. Earth and Planetary Science Letters 128, 601-614.

Azuma, N. Higashi, A., 1985. Formation processes of ice fabric pattern in ice sheets. Annals of Glaciology 6, 130-134.

Bayly, M.B., 1970. Viscosity and anisotropy estimates from measurements on chevron folds. Tectonophysics 9, 459-474.

Bell, T.H., Johnson, S.E., Davis, B., Forde, A., Hayward, N., Wilkins, C., 1992. Porphyroblast inclusion-trail orientation data: eppure-non-son-girate. Journal of Metamorphic Geology 10, 295-307.

Bercovici, D., 2003. The generation of plate tectonics from mantle convection. Earth and Planetary Science Letters 205, 107-121.

Bercovici, D., 2014. Plate tectonics, damage and inheritance. Nature 508, 513516.

Biot, M.A., 1961. Theory of folding of stratified viscoelastic media and its implication in tectonics and orogenesis. Geological Society of America Bulletin 72, 1595-1632.

Bons, P.D., Barr, T.D., ten Brink, C.E., 1997. The development of delta-clasts in non-linear viscous materials: a numerical approach. Tectonophysics 270 , $29-41$.

Bons, P.D., Koehn, D., Jessell, M.W. (Eds.), 2008. Microdynamics simulation. In: Lecture Notes in Earth Science 106. Springer, Berlin. 
Bons, P.D., Jansen, D., Mundel, F., Bauer, C.C., Binder, T., Eisen, O., Jessell, M.W., Llorens, M.-G., Steinbach, F., Steinhage, D., Weikusat, I., 2016. Converging flow and anisotropy cause large-scale folding in Greenland ice sheet. Nature Communications 7, doi: 10.1038/ncomms11427.

Braun, J., Chery, J., Poliakov, A., Mainprice, D., Vauchez, A., Tommasi, A., Daignieres, M., 1999. A simple paramaterization of strain localization in the ductile regime due to grain size reduction: a case study for olivine. Journal of Geophysical Research 104, 25167-25181.

Carreras, J., 2001. Zooming on Northern Cap de Creus shear zones. Journal of Structural Geology 23, 1457-1486.

Carter, N.L., Tsenn, M.C., 1987. Flow properties of the continental lithosphere. Tectonophysics 136, 27-63.

Cobbold, P.R., Cosgrove, J.W., Summers, J.M., 1971. Development of internal structures in deformed anisotropic rocks. Tectonophysics 12, 23-53.

Dabrowski, M., Schmid, D.W., 2011. A rigid circular inclusion in an anisotropic host subject to simple shear. Journal of Structural Geology 33, 1169-1177.

Dabrowski, M., Schmid, D.W., Podladchikov, Y.Y., 2012. A two-phase composite in simple shear: Effective mechanical anisotropy development and localization potential. Journal of Geophysical Research 117, B08406, doi: 10.1029/2012JB009183.

de Bresser, J.H.P., ter Heege, J.H., Spiers, C.J., 2001. Grain size reduction by dynamic recrystallization: can it result in major rheological weakening? International Journal of Earth Sciences 90, 28-45.

Delle Piane, C., Wilson, C.J.L., Burlini, L., 2009. Dilatant plasticity in high-strain experiments on calcite-muscovite aggregates. Journal of Structural Geology 31, 1084-1099.

Dennis, A.J., Secor, D.T., 1987. A model for the development of crenulations in shear zones with applications from the Southern Appalachian Piedmont. Journal of Structural Geology 9, 809-817.

Dieterich, J.H., 1970. Computer experiments on mechanics of finite-amplitude folds. Canadian Journal of Earth Sciences 7, 467-476. 
Druguet, E., Passchier, C.W., Carreras, J., Victor, P., den Brok, S.W.J., 1997. Analysis of a complex high-strain zone at Cap de Creus, Spain. Tectonophysics 280, $31-45$.

Eshelby, J.D., 1957. The determination of the elastic field of an ellipsoidal inclusion and related problems. Proceedings of the Royal Society of London Series A 241, 376-396.

Etchecopar, A., 1977. A plane kinematic model of progressive deformation in a polycrystalline aggregate. Tectonophysics 39, 121-139.

Fay, C., Bell, T.H., Hobbs, B.E., 2008, Porphyroblast rotation versus nonrotation: Conflict resolution! Geology 36, 307-310.

Fletcher, R.C., 1974. Wavelength selection in the folding of a single layer with power-law rheology. American Journal of Science 274, 1029-1043.

Fletcher, R.C., 2009. Deformable, rigid, and inviscid elliptical inclusions in a homogeneous incompressible anisotropic viscous fluid. Journal of Structural Geology 31, 382-387.

Frost, H.J., Ashby, M.F., 1983. Deformation-Mechanism Maps: the Plasticity and Creep of Metals and Ceramics. Pergamon, Oxford.

Fusseis, F., Handy, M. R., Schrank, C., 2006. Networking of shear zones at the brittle-to-viscous transition (Cap de Creus, NE Spain). Journal of Structural Geology 28, 1228-1243.

Gardner, R., Piazolo, S., Evans, L., Daczko, N., 2017. Patterns of strain localization in heterogeneous, polycrystalline rocks - a numerical perspective. Earth and Planetary Science Letters 463, 253-265.

Ghosh, S.K., Ramberg, H., 1976. Reorientation of inclusions by combination of pure and simple shear. Tectonophysics 34, 1-70.

Gomez-Rivas, E., Bons, P.D., Griera, A., Carreras, J., Druguet, E. Evans, L., 2007. Strain and vorticity analysis using small-scale faults and associated drag folds. Journal of Structural Geology 29, 1882-1899.

Gomez-Rivas, E., Griera, A., Llorens, M.-G., Bons, P. D., Lebensohn, R. A., Piazolo, S., 2017. Subgrain rotation recrystallization during shearing: Insights from full-field numerical simulations of halite polycrystals. Journal of Geophysical Research: Solid Earth 122, doi: 10.1002/2017JB014508. 
Goodwin, L.B., Tikoff, B., 2002. Competency contrast, kinematics, and the development of foliations and lineations in the crust. Journal of Structural Geology 24, 1065-1085.

Grasemann, B., Dabrowski, M., 2015. Winged inclusions: Pinch-and-swell objects during high-strain simple shear. Journal of Structural Geology 70, 78-94.

Griera, A., Bons, P.D., Jessell, M.W., Lebensohn, R.A., Evans, L., Gomez-Rivas, E., 2011. Strain localization and porphyroclast rotation. Geology 39, 275-278. Griera, A., Llorens, M.-G., Gomez-Rivas, E., Bons, P.D., Jessell, M.W., Evans, L.A., Lebensohn, R., 2013. Numerical modelling of porphyroclast and porphyroblast rotation in anisotropic rocks. Tectonpophysics 587, 4-29.

Hanmer, S., Passchier, C.W., 1991. Shear sense indicators: a review. Geological Survey of Canada 90,1-71.

Hobbs, B., Regenauer-Lieb, K., Ord, A., 2008. Folding with thermal-mechanical feedback. Journal of Structural Geology 30, 1572-1592.

Houseman, G., Barr, T., Evans, L., 2008. Basil: stress and deformation in a viscous material. In: Bons, P.D., Koehn, D., Jessell, M.W. (Eds.), Microdynamics Simulation. In: Lecture Notes in Earth Sciences 106. Springer, Berlin.

Hudleston, P.J., Lan, L., 1993. Information from fold shapes. Journal of Structural Geology 15, 253-264.

Hudleston, P.J., Lan, L.B., 1994. Rheological control on the shapes of single-layer folds. Journal of Structural Geology 16, 1007-1021.

Hudleston, P.J., Treagus, S.H., 2010. Information from folds: A review. Journal of Structural Geology 32, 2042-2071.

Jansen, D., Llorens, M.-G, Westhoff, J., Steinbach, F., Kipfstuhl, S., Bons, P.D., Griera, A., Weikusat, I., 2016. Small-scale disturbances in the stratigraphy of the NEEM ice core: observations and numerical model simulations. The Cryosphere 10, 359-370.

Jeffery, G.B., 1922. The motion of ellipsoidal particles immersed in a viscous fluid. Proceedings of the Royal Society of London Series A 102, 161-179.

Jessell, M., Bons, P.D., Evans, L., Barr, T., Stüwe, K., 2001. Elle: the numerical simulation of metamorphic and deformation microstructures. Computers \& Geosciences 27, 17-30. 
Jessell, M.W., Siebert, E., Bons, P.D., Evans, L., Piazolo, S., 2005. A new type of numerical experiment on the spatial and temporal patterns of localization of deformation in a material with a coupling of grain size and rheology. Earth and Planetary Science Letters 239, 309-326.

Jessell, M.W., Bons, P.D., Griera, A., Evans, L.A., Wilson, C.J.L., 2009. A tale of two viscosities. Journal of Structural Geology 31, 719-736.

Jezek, J., 1994. Software for modeling the motion of rigid triaxial ellipsoidal particles in viscous-flow. Computers \& Geosciences 20, 409-424.

Jiang, D. 2016. Viscous inclusions in anisotropic materials: Theoretical development and perspective applications. Tectonophysics 693, 116-142.

Kamb, W. B. 1972. Experimental recrystallization of ice under stress. American Geophysical Union Monograph 16, 221-241.

Kaus, B.K.P., Podladchikov, Y.Y., 2006. Initiation of localized shear zones in viscoplastic rocks. Journal of Geophysical Research 111, B04412, doi : 10.1029/2005JB003652.

Kirby, S.H., 1983. Rheology of the lithosphere. Reviews of Geophysics and Space Physics 21, 1458-1487.

Kocher, T., Schmalholz, S.M., Mancktelow, N.S., 2006. Impact of mechanical anisotropy and power-law rheology on single layer folding. Tectonophysics 421, 71-87.

Kocher, T., Mancktelow, N.S., Schmalholz, S.M., 2008. Numerical modelling of the effect of matrix anisotropy orientation on single layer fold development. Journal of Structural Geology 30, 1013-1023.

Kröner, E. 1961. On the plastic deformation of polycrystals. Acta Metallurgica 9, 155-161.

Lebensohn, R.A., 2001. N-site modelling of a 3D viscoplastic polycrystal using fast Fourier transform. Acta Materialia 49, 2723-2737.

Lebensohn, R.A., Brenner, R., Castelnau, O., Rollett, A.D., 2008. Orientation imagebased micromechanical modelling of subgrain texture evolution in polycrystalline copper. Acta Materialia 56, 3914-3926.

Lebensohn, R.A., Montagnat, M., Mansuy, P., Duval, P., Meysonnier, J., Philip, A., 2009. Modeling viscoplastic behavior and heterogenous intracrystalline deformation of columnar ice polycrystals. Acta Materialia 57, 1405-1415. 
Lister, G.S., Paterson, M.S., Hobbs, B.E., 1978. The simulation of fabric development during plastic deformation and its application to quartzite: the model. Tectonophysics 45, 107-158.

Llorens, M.-G., Bons, P.D., Griera, A., Gomez-Rivas, E., 2013a. When do folds unfold during progressive shearing? Geology 41, 563-566.

Llorens, M.-G., Bons, P.D., Griera, A., Gomez-Rivas, E., 2013b. Single layer folding in simple shear. Journal of Structural Geology 50, 209-220.

Llorens, G.-M., Griera, A., Bons, P.D., Lebensohn, R.A., Evans, L.A., Jansen, D., Weikusat, I. 2016a. Full-field predictions of ice dynamic recrystallisation under simple shear conditions. Earth and Planetary Science Letters 450, 233-242.

Llorens, G.-M., Griera, A., Weikusat, I., Bons, P.D., Roessiger, J., Lebensohn, R.A. 2016b. Dynamic recrystallisation of ice aggregates during co-axial viscoplastic deformation: a numerical approach. Journal of Glaciology 62, 359-377.

Llorens, M.-G., Griera, A., Steinbach, F., Bons, P.D., Gomez-Rivas, E., Jansen, D., Roessiger, J., Lebensohn, R.A., Weikusat, I., 2017. Dynamic recrystallization during deformation of polycrystalline ice: insights from numerical simulations. Philosophical Transactions Series A: Mathematical, physical, and engineering sciences 375,2086 , doi: 10.1098/rsta.2015.0346.

Mancktelow, N.S., 1999. Finite-element modelling of single-layer folding in elastoviscous materials; the effect of initial perturbation geometry. Journal of Structural Geology 21, 161-177.

Mancktelow, N.S., 2011. Deformation of an elliptical inclusion in two-dimensional incompressible power-law viscous flow. Journal of Structural Geology 33, 1378-1393.

Mancktelow, N.S., 2013. Behaviour of an isolated rimmed elliptical inclusion in 2D slow incompressible viscous flow. Journal of Structural Geology 46, 235-254.

Mandal, N., Samanta, S.K., Chakraborty, C., 2000. Progressive development of mantle structures around elongate porphyroclasts: insights from numerical models. Journal of Structural Geology 22, 993-1008. 
Marmo, B.A., Wilson, C.J., 1998. Strain localisation and incremental deformation within ice masses, Framnes Mountains, east Antarctica. Journal of Structural Geology 20, 149-162.

Marques, F.O., Taborda, R., Antunes, J., 2005a. Influence of a low-viscosity layer between rigid inclusion and viscous matrix on inclusion rotation and matrix flow: a numerical study. Tectonophysics 407, 101-115.

Marques, F.O., Taborda, R., Bose, S., Antunes, J., 2005b. Effects of confinement on matrix flow around a rigid inclusion in viscous simple shear: insights from analogue and numerical modelling. Journal of Structural Geology 27, 379396.

Marques, F.O., Mandal, N., Taborda, R., Antunes, J.V., Bose, S., 2014. The behaviour of deformable and non-deformable inculsions in viscous flow. EarthScience Reviews 134, 16-69.

Montagnat, M., Castelnau, O., Bons, P.D., Faria, S.H., Gagliardini, O., Gillet-Chaulet, F., Grennerat, F., Griera, A., Lebensohn, R.A., Moulinec, H., Roessiger, J., Suquet, P., 2014. Multiscale modeling of ice deformation behavior. Journal of Structural Geology 61, 78-108.

Montési, L.G.J., 2013. Fabric development as the key for forming ductile shear zones and enabling plate tectonics. Journal of Structural Geology 50, 254266.

Mühlhaus, H.-B., Moresi, L., Hobbs, B., Dufour, F., 2002. Large amplitude folding in finely layered viscoelastic rock structures. Pure and Applied Geophysics $159,2311-2333$.

Passchier, C. W., 1991. The classification of dilatant flow types. Journal of Structural Geology 13, 101-104.

Passchier, C.W., Simpson, C., 1986. Porphyroclast systems as kinematic indicators. Journal of Structural Geology 8, 831-843.

Passchier, C.W., Sokoutis, D., 1993. Experimental modelling of mantle porphyroclasts. Journal of Structural Geology 15, 895-909.

Passchier, C.W., Trouw, R.A.J., 2005. Deformation mechanisms. Microtectonics, Springer, Berlin.

Passchier, C.W., Trouw, R.A.J., Zwart, H.J., Vissers, R.L.M., 1992. Porphyroblast rotation - Eppur-Si-Muove. Journal of Metamorphic Geology 10, 283-294. 
Piazolo, S., Jessell, M.W., Bons, P.D., Evans, L., Becker, J.K., 2010. Numerical simulations of microstructures using the Elle platform: A modern research and teaching tool. Journal of the Geological Society of India 75, 110-127.

Platt, J.P., 1984. Secondary cleavages in ductile shear zones. Journal of Structural Geology 6, 439-442.

Platt, J.P., Vissers, R.L.M., 1980. Extensional structures in anisotropic rocks. Journal of Structural Geology 2, 397-410.

Platt, J.P., Behr, W.M., 2011. Grainsize evolution in ductile shear zones: Implications for strain localization and the strength of the lithosphere. Journal of Structural Geology 33, 537-550.

Ramberg, H., 1962. Contact strain and folding instability of a multilayered body under compression. Geologische Rundschau 51, 405-439.

Ramsay, J.G., Huber, M.I., 1987. The Techniques of modern structural geology, vol. 2: Folds and Fractures. Academic Press, London.

Schmalholz, S.M., 2006. Finite amplitude folding of single layers: elastica, bifurcation and structural softening. Philosophical Magazine 86, 33933407.

Schmalholz, S.M., Maeder, X., 2012. Pinch-and-swell structure and shear zones in viscoplastic layers. Journal of Structural Geology 37, 75-88.

Schmalholz, S.M., Mancktelow, N.S., 2016. Folding and necking across the scales: a review of theoretical and experimental results and their applications. Solid Earth 7, 1417-1465.

Schmalholz, S.M., Podladchikov, Y., 1999. Buckling versus folding: Importance of viscoelasticity. Geophysical Research Letters 26, 2641-2644.

Schmalholz, S.M., Podladchikov, Y.Y., Schmid, D.W., 2001. A spectral/finite difference method for simulating large deformations of heterogeneous, viscoelastic materials. Geophysical Journal International 145, 199-208.

Schmid, D.W., Podladchikov, Y.Y., 2005. Mantled porphyroclast gauges. Journal of Structural Geology 27, 571-585.

Schrank, C.E., Handy, M.R., Fusseis, F., 2008. Multiscaling of shear zones and the evolution of the brittle-to-viscous transition in continental crust. Journal of Geophysical Research: Solid Earth 113, doi: 10.1029/2006JB004833. 
Steinbach, F., Bons, P.D., Griera, A., Jansen, D., Llorens, M.-G., Roessiger, J., Weikusat, I., 2016. Strain localisation and dynamic recrystallisation in the ice-air aggregate: A numerical study. The Cryosphere 10, 3071-3089.

Steinbach, F., Kuiper, E.J.N., Eichler, J., Bons, P.D., Drury, M.R., Griera, A., Pennock, G.M., Weikusat, I., 2017. The Relevance of Grain Dissection for Grain Size Reduction in Polar Ice: Insights from Numerical Models and Ice Core Microstructure Analysis. Frontiers in Earth Science 5, 66, doi: 10.3389/feart.2017.00066.

Taylor, G.I., 1938. Plastic strain in metals. J. Inst. Metals, 62, 307-324. ten Grotenhuis, S.M., Passchier, C.W., Bons, P.D,. 2002. The influence of strain localisation on the rotation behaviour of rigid objects in experimental shear zones. Journal of Structural Geology 24, 485-499.

Treagus, S.H., 1982. A new isogon-cleavage classification and its application to natural and model fold studies. Geological Journal 17, 49-64.

Tullis, J., Yund, R.A., 1985. Dynamic recrystallization of feldspar: a mechanism for ductile shear zone formation. Geology 13, 238-241.

Viola, G., Mancktelow, N.S., 2005. From XY tracking to buckling: axial plane cleavage fanning and folding during progressive deformation. Journal of Structural Geology 27, 409-417.

Watkinson, A.J., 1983. Patterns of folding and strain influenced by linearly anisotropic bands. Journal of Structural Geology 5, 449-454.

Weijermars, R., 1992. Progressive deformation in anisotropic rocks. Journal of Structural Geology 14, 723-742.

White, S., 1979. Large strain deformation: report on a tectonic studies group discussion meeting held at Imperial College, London on 14 November 1979. Journal of Structural Geology 1, 333-339.

Wilson, C.J.L., 1984. Shear bands, crenulations and differentiated layering in icemica models. Journal of Structural Geology 6, 303-319.

Zhang, Y., Hobbs, B.E. Jessell, M.W., 1993. Crystallographic preferred orientation development in a buckled single layer: a computer simulation. Journal of Structural Geology 15, 265-276.

Zhang, Y., Mancktelow, N.S., Hobbs, B.E., Ord, A., Mühlhaus, H.B., 2000. Numerical modelling of single-layer folding: clarification of an issue regarding the 
possible effects of computer codes and the influence of initial irregularities. Journal of Structural Geology 22, 1511-1522. 


\section{Figure captions}

Fig. 1. (a) Folded quartz vein in biotite-schist matrix at Puig Culip (Cap de Creus, Eastern Pyrenees, Spain). The matrix has a first cleavage ( $S_{1}$, solid yellow lines) that is crenulated to develop an $\mathrm{S}_{2}$-cleavage (white dashed lines), axial planar to the vein folds. One Euro coin for scale, $\emptyset=23 \mathrm{~mm}$. (b-c) Finite-element simulations of folding of a single competent layer embedded in a weaker, isotropic matrix (same as presented in Llorens et al., 2013a,b). (b) dextral simple shear up to a shear strain of 2, and (c) vertical pure shear up to 55\% shortening. (d-e) VPFFT-ELLE simulations of single layer folding in an anisotropic matrix $(A=20)$ in (d) dextral simple shear up to a shear strain of 1 , and (e) vertical pure shear up to $50 \%$ shortening. Note that the anisotropy in the matrix results in an axial planar crenulation cleavage, comparable to the one shown in (a). Grey area in insets is area of model shown.

Fig. 2. VPFFT-ELLE-simulations of a circular hard object (dark red), deformed to a dextral simple shear strain of ten, with a softer mantle (black), embedded in an (a) isotropic or (b) anisotropic matrix $(A=10)$. Strain distribution is illustrated by the boundaries of the originally equidimensional elements. White arrows show the total amount of rotation of the objects. Ongoing rotation of the object in the isotropic matrix leads to the development of a $\delta$-clast, while an anisotropic matrix leads to strongly heterogeneous matrix deformation, reduced object rotation and, hence, development of a $\sigma$-clast.

Fig. 3. C' shear bands in (a) a naturally deformed rock and (b) an VPFFT-ELLE simulation with a weak (black), intermediate (white) and strong (pink) phase. St = staurolite, $\mathrm{Qtz}=$ quartz, $\mathrm{Bt}=$ biotite. The S-foliation is highlighted with blue lines, C-planes with green lines and C'-planes with dashed green lines.

Fig. 4. VPFFT-ELLE simulations of polycrystals deformed in dextral simple shear up to a shear strain of 3 and with increasing degree of grain anisotropy $(A)$ from 1 to 20 . Anisotropy is defined as the ratio between the critical resolved shear stress $\left(\tau_{c r}\right)$ required to activate the non-basal and basal slip systems. (a) Grain 
boundary network and (b) Von-Mises shear strain rate field, normalized with respect to the bulk value. For better visibility figures of Von Mises strain rate field have been enlarged two times, only showing the lower right quarter of the model. (c) Frequency distribution of normalised Von-Mises strain rates for different anisotropy values. Whereas the distribution for $A=1$ is approximately normal with a mean of one, higher $A$-values lead to a frequency peak below the mean and a "heavy tail" of high strain rate values. Inset shows the same data, but with a linear vertical scale.

\section{Table caption}

Table 1. Summary of method, deformation and properties of the models described in the text. All models were run using the ELLE platform. 

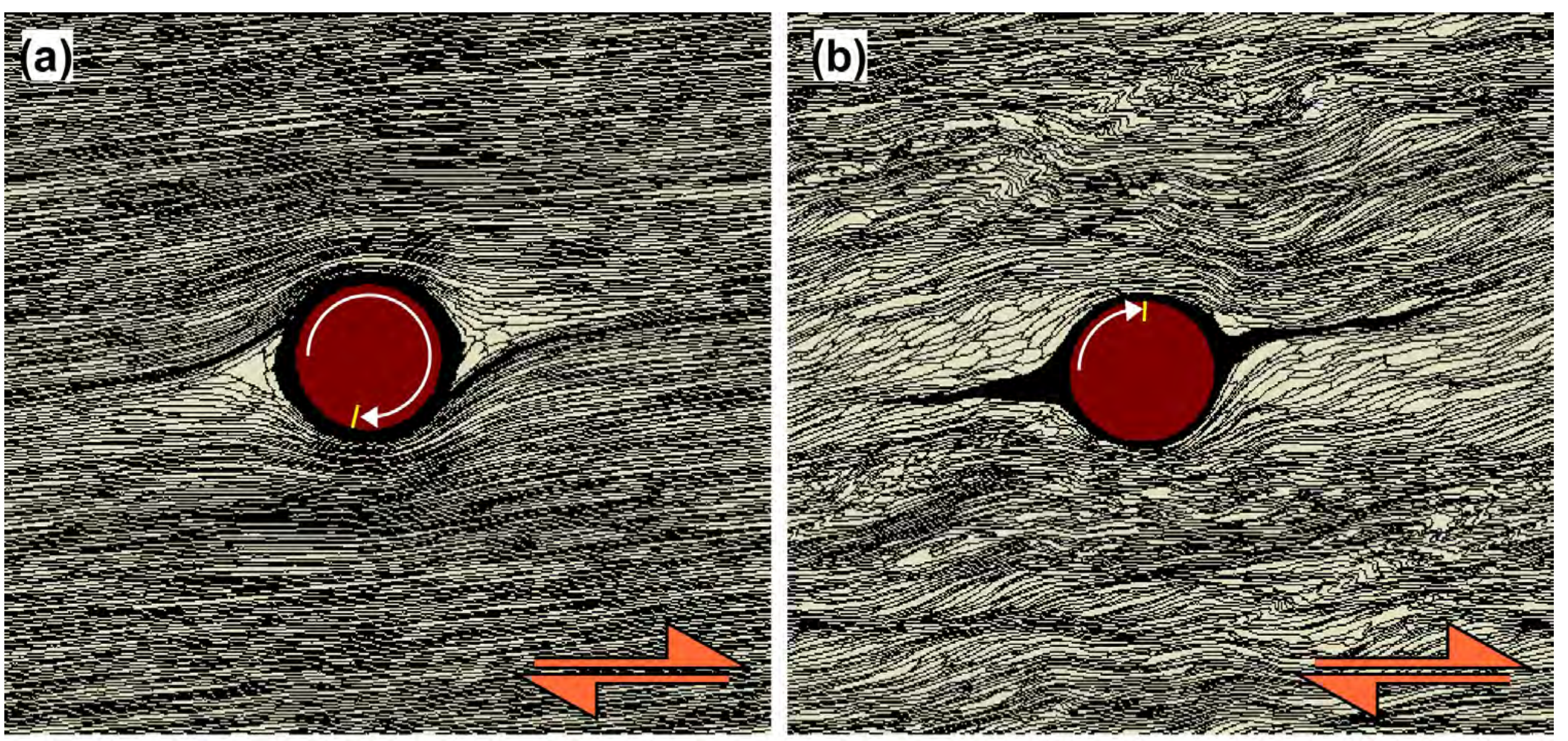

Figure 2 

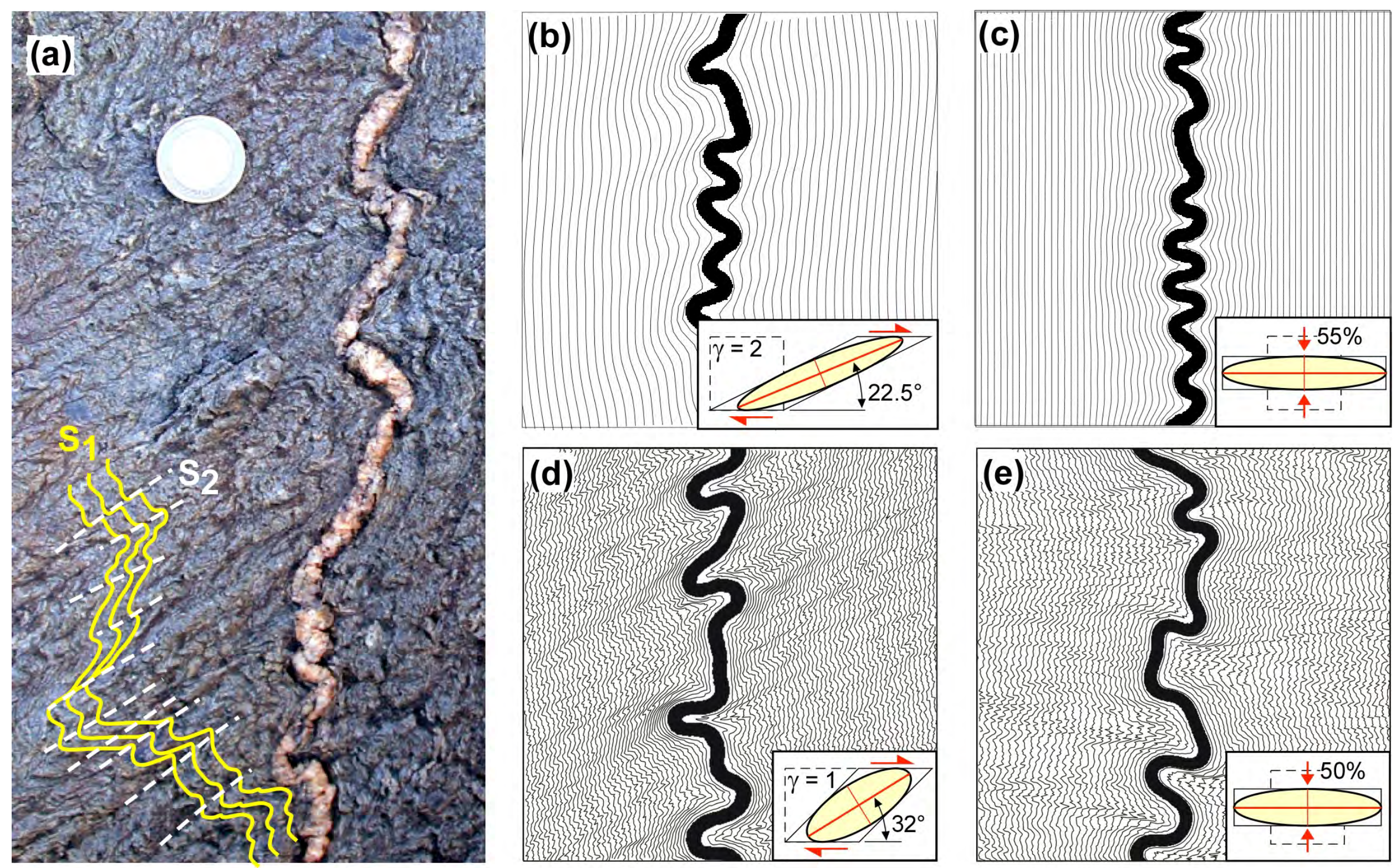

Figure 1 

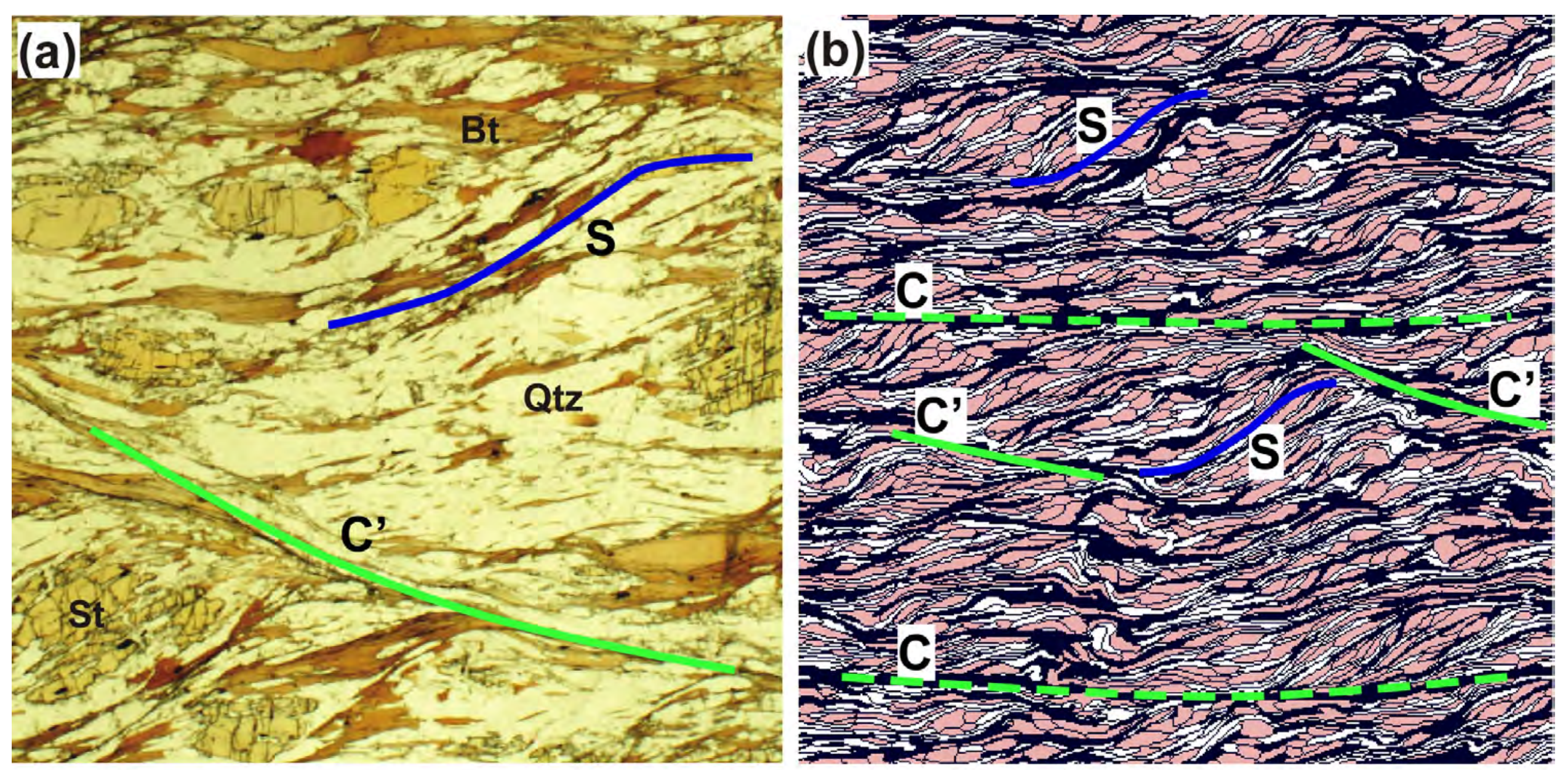

Figure 3 

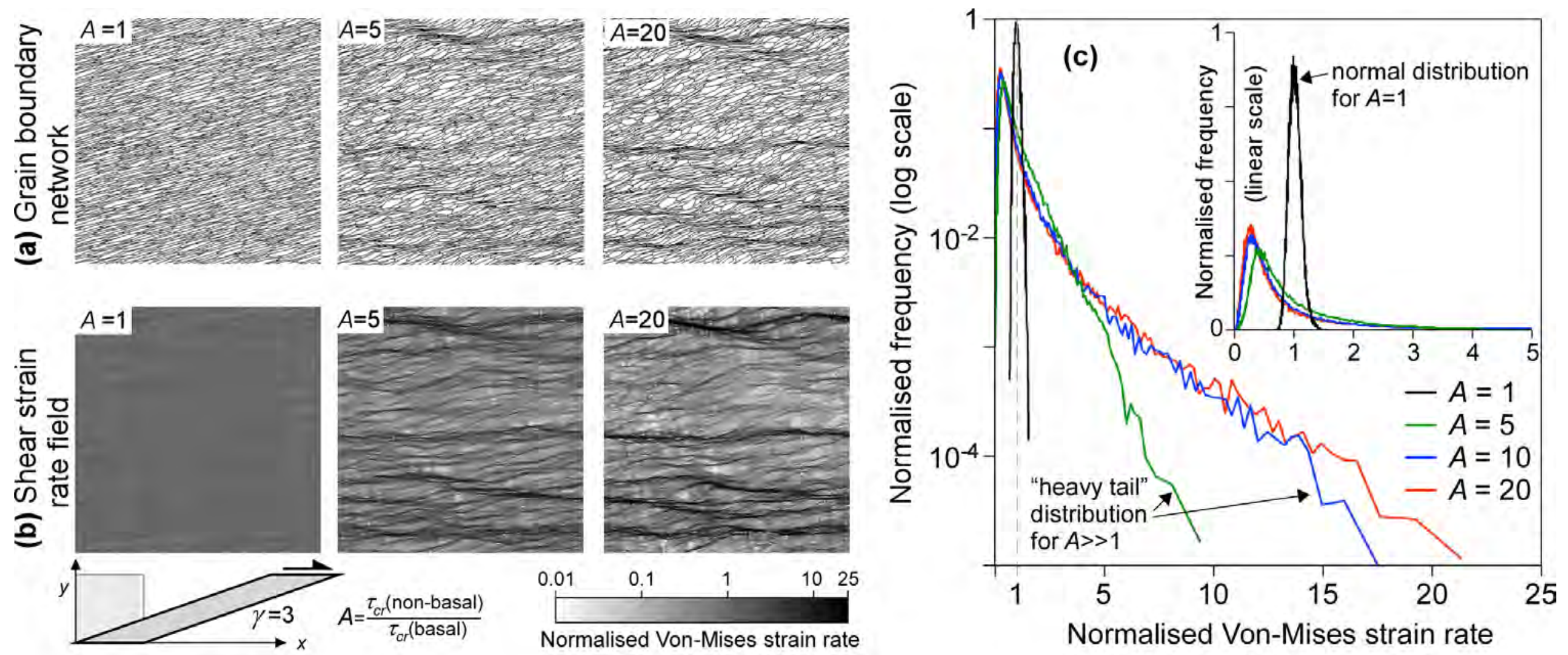

Figure 4 
Table 1

\begin{tabular}{|c|c|c|c|c|c|}
\hline Figure & Method $^{1}$ & Deformation & Properties & & \\
\hline & & & Layer & Matrix & \\
\hline Fig. 1b & FEM & simple shear & $B=50$ & $B=1$ & \\
\hline Fig. 1c & FEM & pure shear & $B=50$ & $B=1$ & \\
\hline Fig. 1d & VPFFT & simple shear & $\tau_{c r}($ all $)=100$ & $\tau_{c r}($ basal $)=1$ & \\
\hline Fig. 1e & VPFFT & pure shear & $\tau_{c r}($ all $)=100$ & $\begin{array}{l}\tau_{c r}(\text { other })=20 \\
\tau_{c r}(\text { basal })=1 \\
\tau_{c r}(\text { other })=20\end{array}$ & \\
\hline $\begin{array}{l}\text { Fig. 2a } \\
\text { Fig. 2b }\end{array}$ & $\begin{array}{l}\text { VPFFT } \\
\text { VPFFT }\end{array}$ & $\begin{array}{l}\text { simple shear } \\
\text { simple shear }\end{array}$ & $\begin{array}{l}\text { Core object } \\
\tau_{c r}(\text { all })=50 \\
\tau_{c r}(\text { all })=50\end{array}$ & $\begin{array}{l}\text { Mantle } \\
\tau_{c r}(\text { all })=0.8 \\
\tau_{c r}(\text { all })=4\end{array}$ & $\begin{array}{l}\text { Matrix } \\
\tau_{c r}(\text { all })=1 \\
\tau_{c r}(\text { basal })=1 \\
\tau_{c r}(\text { other })=10\end{array}$ \\
\hline Fig. $3 b$ & VPFFT & simple shear & $\begin{array}{l}\text { Strong phase } \\
\tau_{c r}(\text { all })=30\end{array}$ & $\begin{array}{l}\text { Intermediate } \\
\tau_{c r}(\text { all })=15\end{array}$ & $\begin{array}{l}\text { Weak phase } \\
\tau_{c r}(\text { basal })=1 \\
\tau_{c r}(\text { other })=10\end{array}$ \\
\hline Fig. 4 & VPFFT & simple shear & $\begin{array}{l}\text { Whole model } \\
\tau_{c r} \text { (basal) }=1 \\
\tau_{c r}(\text { other })=1,5,20\end{array}$ & & \\
\hline
\end{tabular}

${ }^{1}$ FEM = finite element method with BASIL (Houseman et al., 2008). VPFFT= Viscoplastic FullField Transform method (Lebensohn, 2001), using 256x256 elements. 